\title{
Analisis Tingkat Kepuasan Pengunjung Terhadap Fasilitas Umum Di Bandar Udara Abdulrachman Saleh Malang
}

\author{
Mutiara Firdausi ${ }^{1}$ \\ ${ }^{1}$ Jurusan Teknik Sipil, FTSP, Institut Teknologi Adhi Tama Surabaya, Surabaya \\ E-mail: mutiara_firdausi89@yahoo.com.
}

\begin{abstract}
ABSTRAK: Rencana pemerintah merubah sistem Bandara Abdulrachman Saleh Malang dari domestik menjadi internasional tentunya memerlukan pengembangan kualitas pelayan serta fasilitas umum yang memadai. Bandar Udara Abdulrachman Saleh Malang sebaiknya melakukan evaluasi terhadap tingkat kepuasan pengunjung. Populasi pengunjung dalam 5 tahun terakhir 20132017 mencapai 765.804 orang per tahun. Sampel pada penelitian ini adalah penumpang yang menunggu jadwal keberangkatan di ruang tunggu, jumlah responden dihitung dengan rumus Slovin sebanyak 121 responden, pengumpulan sampel menggunakan kuesioner. Teknik pengambilan sampel menggunakan Probability Sampling. Metode pada penelitian ini adalah CSI untuk mengukur tingkat kepuasan. Hasil penelitian menunjukan tingkat kepuasan pengunjung terhadap fasilitas umum di Bandar Udara Abdulrachman Saleh Malang adalah 77,43 \% masuk dalam kategori Puas. Ketidakpuasan pelanggan terhadap kinerja pelayanan dan fasilitas menunjukkan 23,57\% responden yang menyatakan tidak puas terhadap kehandalan peralatan dan fasilitas seperti, AC, Televisi dan lainnya, kemudahan mendapatkan inter-moda seperti, taksi, bis, dan lainnya, serta acara khusus yang diadakan pihak bandara seperti, promo tiket di waktu tertentu.
\end{abstract}

KEYWORDS : CSI (Customer Satisfaction Index), Tingkat Kepuasan, Kinerja Pelayanan, Bandar Udara Abdulrachman Saleh Malang

\section{LATAR BELAKANG}

Kondisi Kota Malang yang menjadi kota pendidikan dan pariwisata berakibat pada kenaikan jumlah wisatawan yang berkunjung ke Kota Malang. Para wisatawan tersebut tergolong variatif, antara lain untuk melanjutkan pendidikan, berwirausaha atau berwisata (Zulaichah, 2013).Pengguna layanan transportasi udara di Bandar Udara Abdulrachman Saleh Malang pada tahun 2013 sampai tahun 2017 mengalami peningkatan rata-rata 1,2 $\%$ pertahun dengan jumlah rata-rata 765.804,6 pengunjung pertahun. Pemerintah Provinsi Jawa Timur Berencana akan meningkatkan status Bandar Udara Abdulrachman Saleh dari bandar udara domestik menjadi bandar udara internasional (Zulaichah, 2013) perubahan sistem bandara ini tentunya harus didukung dengan kualitas pelayanan dan fasilitas yang baik. Rencana pengembangan bandara terhadap fasilitas yang akan dibangun diharapkan dapat meningkatkan kenyamanan, keamanan, dan kemudahan bagi para pendatang. Selain ruang terminal dan fasilitas sisi udara, fasilitas bandara juga berhubungan dengan penyediaan fasilitas inter-moda dari dan menuju bandara (Wibowo, 2017).

Menurut penelitian terdahulu, Kajian Tingkat Kepuasan Penumpang dan Kinerja Pelayanan Terminal Penumpang Domestik (T2) di Bandar Udara Internasional Juanda Surabaya ini menggunakan 3 metode pengujian tingkat kepuasan, salah satunya dengan metode CSI (Customer Satisfaction Index) (Mariana, 2015) kelebihan metode CSI adalah menghitung indeks kepuasan per atribut pelayanan secara keseluruhan dan penelitian tersebut menunjukan bahwa metode CSI dapat menjadi rujukan standardisasi pengukuran kepuasan pengunjung terhadap fasilitas umum di bandara intenasional. Tingkat kualitas layanan tidak dapat dinilai berdasarkan sudut pandang perusahaan, tapi harus dipandang dari sudut pandang penilaian pelanggan (Darus, 2015) pengunjung di Bandar Udara Abdulrachman Saleh Malang memiliki peranan penting dalam menentukan kepuasan terhadap tingkat pelayanan dan fasilitas yang disediakan. Fasilitas umum penumpang di dalam Bandar Udara Abdulrachman Saleh Malang tidak hanya menyesuaikan standardisasi fasilitas bandara, tetapi juga dari tanggapan pengunjung yang menggunakan layanan tersebut.

\section{METODE PENELITIAN}

Penelitian ini menggunakan metode penyebaran kuesioner. Data primer untuk penelitian ini meliputi data kuesioner.

\section{Pengumpulan Data}

Sumber data dalam penelitian ini ada 2 yaitu Data Primer dan Data Sekunder sebagai berikut :

- Data Primer dalam penelitian didapat dengan melakukan survei karakteristik dan presepsi penumpang secara langsung kepada pengunjung Bandar Udara Abdulrachman Saleh Malang dengan menggunakan kuesioner.

- Sedangkan Data Sekunder yang didapat dari pihak UPT (Unit Pelaksana Teknis) Bandar Udara Abdulrachman Saleh Malang antara lain, data jumlah pengunjung 5 tahun terakhir dan data layout (denah) bandara. Populasi penelitian ini yaitu pengunjung Bandar Udara Abdulrachman Saleh Malang. Yang menjadi unit sampling (ciri - ciri responden) adalah pengunjung yang menunggu keberangkatan di Ruang Tunggu.

- Kualitas layanan merupakan perbandingan antara pelayanan dengan kualitas layanan yang diharapkan oleh konsumen. Berdasarkan pendapat tersebut dapat diketahui bahwa kualitas pelayanan adalah memberikan kesempurnaan pelayanan untuk tercapainya keinginan atau harapan pelanggan. Terdapat lima kualitas pelayanan yaitu Bukti Fisik (tangibles), Keadaan (realiability), Daya Tanggap (responsiveness), Jaminan (assurance), dan Empati (empathy) (Selvy, 2013). Adapun dimensi kualitas jasa yang baik dari sisi perusahaan adalah sebagai berikut :

a. Bukti fisik (Tangibles)

Penampilan fasilitas fisik, peralatan, petugas, dan materi komunikasi. 
b. Kehandalan (Realibility)

Kemampuan untuk melakukan atau melaksanakan jasa dan menyajikan layanan yang konsisten dan tepat waktu.

c. Daya tanggap (Responsiveness)

Merupakan salah satu pelayanan yang digunakan dalam membantu serta memberikan kemudahan-kemudahan yang ditujukan pada pelanggan.

d. Jaminan (Assurance)

Merupakan jaminan yang diberikan oleh perusahaan dalam memberi keamanan kepada pelanggan.

e. Empati (Empathy)

Merupakan sikap perusahaan yang memihak pada pelanggan atau membela pelanggan.

\section{Kepuasan Pelanggan}

Kepuasan pelanggan adalah tingkat perasaan seseorang setelah membandingkan kinerja (atau hasil) dari suatu pelayanan jasa yang dirasakan dengan harapannya (Selvy, 2013).

\section{Penentuan Jumlah Sampel}

Sampel adalah bagian dari jumlah dan karakteristik yang dimiliki oleh populasi. Pengambilan sampel dalam penelitian ini dengan teknik probability sampling dengan menggunakan rumus Slovin. Probability sampling adalah teknik pengambilan sampel yang memberi peluang yang rata pada setiap unsur (anggota) populasi untuk dipilih menjadi anggota sampel (Sugiyono, 2010). Penentuan sampel pada penelitian ini diperoleh dari rumus Slovin yang

meliputi banyaknya populasi. Banyaknya populasi tersebut didapat dari data sekunder yaitu data jumlah pengunjung 5 tahun terakhir. Penentuan sampel dilakukan sebelum penyebaran kuesioner yang betujuan untuk menentukan banyaknya kuesioner yang akan dibagikan kepada masing-masing responden. Sebelum menentukan banyaknya kuesioner, jumlah sampel dapat dihitung dengan tahapan sebagai berikut:

- Mengetahui jumlah rata-rata populasi yang ada di Bandar Udara Abdulrachman Saleh Malang melalui Data Sekunder, jumlah penumpang 5 tahun terakhir.

- Kuesioner dapat dilihat pada lampiran.

Dalam penelitian ini jumlah Sampel ditentukan menggunakan rumus Slovin sebagai berikut:

$$
\mathrm{n} \quad=\frac{\mathrm{N}}{1+\mathrm{N}(\mathrm{e}))^{2}}
$$

Keterangan :

$\mathrm{n} \quad=$ ukuran sampel.

$\mathrm{N} \quad=$ ukuran populasi.

$\mathrm{E}=$ persen kelonggaran ketidaktelitian karena Kesalahan pengambilan data yang masih dapat ditolerir/diinginkan atau biasa disebut dengan tingkat kepercayaan. Biasanya diambil sebesar $1 \%$ sampai dengan $10 \%$.

Kesalahan yang terjadi karena kebetulan disebut dengan taraf signifikansi, yaitu taraf seberapa besar kemungkinan terjadinya kebenaran karena kebetulan saja benar. Berikut penjelasan tentang Error level (tingkat kesalahan):

a. Untuk ilmu kealaman taraf signifikansi disepakati para ahli (dalam berbagai literatur umumnya menyatakan sama) yang "terbaik" sebesar 0,01 . Maksudnya hanya ada 0,01 atau $1 \%$ saja kesalahan karena kebetulan terjadi. Jadi, dengan kata lain yakin sebesar $99 \%$ bahwa hasil penelitian itu benar. Itu artinya, karena tetap berhati-hati, tidak ada yang "patut" diyakini $100 \%$ benar.

b. Untuk ilmu-ilmu sosial dan pendidikan disepakati yang "terbaik" itu sebesar 0,05. Maksudnya hanya ada 0,05 atau $5 \%$ saja kesalahan karena kebetulan itu terjadi. Jadi, yakin $95 \%$ bahwa hasil penelitian itu benar. Ini karena tingkat kepastian "orang-orang" (sosial) itu relatif tidak seperti gejala kealaman. Dalam pengambilan sampel, kedua aspek tersebut menjadi salah satu perhatian utama. Jika hasil penelitian diharapkan mencapai taraf signifikansi tinggi (taraf kesalahan karena faktor kebetulan kecil), maka jumlah sampel dituntut lebih banyak dibandingkan dengan harapan taraf signifikasi lebih rendah (banyak kesalahan yang disebabkan karena taraf signifikansi lebih besar).

\section{Metode CSI (Customer Satisfaction Index)}

Customer Satisfaction Index (CSI) pada Tebl 1merupakan analisis kuantitatif berupa persentase pelanggan yang sedang dalam suatu survei kepuasan pelanggan. CSI diperlukan untuk mengetahui tingkat kepuasan pelanggan secara keseluruhan dengan memperhatikan tingkat kepentingan dari atribut-atribut produk atau jasa (Pohandry, 2013).

Tabel 1. Customer Satisfaction Index (CSI)

\begin{tabular}{|l|l|l|l|}
\hline Atribut & $\begin{array}{l}\text { Kepentingan } \\
\text { (I) }\end{array}$ & $\begin{array}{l}\text { Kepuasan } \\
(\mathbf{P})\end{array}$ & Skor (S) \\
\hline & Skala 1:5 & Skala 1:5 & $(\mathrm{S})=(\mathrm{I}) \mathrm{x}(\mathrm{P})$ \\
\hline & & & \\
\hline & & & \\
\hline Skor Total & $\begin{array}{l}\text { Total (I) } \\
(\mathrm{Y})\end{array}$ & & $\begin{array}{l}\text { Total }(\mathrm{S})= \\
(\mathrm{T})\end{array}$ \\
\hline
\end{tabular}

Perhitungan keseluruhan CSI diilustrasikan pada Tabel 1 Customer Satisfaction Index (CSI). Nilai rata-rata pada kolom kepentingan (I) dijumlahkan sehingga diperoleh Y dan juga hasil kali I dengan P pada kolom skor (S) dijumlahkan dan diperoleh T. CSI diperoleh dari perhitungan $(\mathrm{T} / 5 \mathrm{Y}) \times 100 \%$. Nilai 5 (pada $5 \mathrm{Y}$ ) adalah nilai maksimum yang digunakan pada skala pengukuran. CSI dihitung dengan rumus:

$C S I=T / 5 Y \times 100 \%$

Nilai maksimum CSI adalah $100 \%$. Nilai CSI $50 \%$ atau lebih rendah menandakan kinerja pelayanan yang kurang baik. Nilai CSI $80 \%$ atau lebih tinggi mengindikasikan pelanggan merasa puas terhadap kinerja pelayanan (Pohandry, 2013). Menurut Irawan (2004), ada 
pengujian dengan metode Customer Satisfaction Index (CSI), terdapat kriteria untuk mengetahui tingkat kepuasan konsumen terhadap kinerja perusahaan (Darus, 2015). Hal ini dapat dilihat pada Tabel 2. berikut:

Tabel 2. Kriteria Tingkat Kepuasan Pelanggan

\begin{tabular}{|c|c|c|}
\hline No & Nilai CSI (\%) & $\begin{array}{c}\text { Keterangan } \\
\text { (CSI) }\end{array}$ \\
\hline $\mathbf{1}$ & $81-100$ & Sangat Puas \\
\hline $\mathbf{2}$ & $66-80,99$ & Puas \\
\hline $\mathbf{3}$ & $51-65,99$ & Cukup Puas \\
\hline $\mathbf{4}$ & $35-50,99$ & Kurang Puas \\
\hline $\mathbf{5}$ & $0-34,99$ & Tidak Puas \\
\hline
\end{tabular}

Setelah menghitung indeks kepuasan pelanggan, untuk menyatakan hasil CSI kepuasan pelanggan, dapat dilihat pada Tabel 2. Kritera Tingkat Kepuasan Pelanggan

\section{HASIL PENELITIAN}

Berikut ini adalah tahapan dalam analisis dalam penelitian ini :

\section{Data Penumpang Bandar Udara Abdulrachman Saleh Malang}

Berdasarkan informasi dari Kantor UPT Bandar Udara Abdulrachman didapat data penumpang 5 tahun terakhir, dapat dilihat pada Tabel 3 dibawah ini :

Tabel 3. Data Penumpang

\begin{tabular}{|c|c|}
\hline Tahun & $\begin{array}{c}\text { Jumlah Penumpang } \\
\text { (Orang) }\end{array}$ \\
\hline $\mathbf{2 0 1 3}$ & 527.167 \\
\hline $\mathbf{2 0 1 4}$ & 626.690 \\
\hline $\mathbf{2 0 1 5}$ & 722.827 \\
\hline $\mathbf{2 0 1 6}$ & 859.878 \\
\hline $\mathbf{2 0 1 7}$ & 1.092 .461 \\
\hline
\end{tabular}

Dari Tabel 3 Data Penumpang 5 Tahun Terakhir menunjukkan peningkatan jumlah penumpang per tahun. Pada tahun 2013 jumlah penumpang mencapai 527.167 orang. Pada tahun 2014 jumlah penumpang mencapai 626.690 orang. Pada tahun 2015 jumlah penumpang mencapai 722.827 orang. Pada tahun 2016 jumlah penumpang mencapai 859.878 orang. Pada tahun 2017 jumlah penumpang mencapai 1.092.461 orang

\section{Analisis Data Penumpang Menggunakan Rumus Slovin}

Jumlah responden kuesioner dapat dicari menggunakan rumus Slovin. Populasi yang terdapat dalam penelitian ini berjumlah 765.804 orang/tahun sedangkan, error level (e) atau taraf signifikansi untuk sosial dan pendidikan lazimnya 0,05 . Pada penelitian ini digunakan 0,1 , maka banyaknya sampel dalam penelitian ini adalah 100 sampel. Untuk mengurangi tingkat kesalahan saat analisis data maka jumlah responden ditambah menjadi 121 sampel.

\section{Hasil Rekapitulasi Karakteristik Penumpang}

Hasil rekapitulasi karakteristik penumpang pada peneltian ini lengkapnya terdapat pada Tabel 4.

Tabel 4. Rekapitulasi Karakteristik Penumpang

\begin{tabular}{|l|l|l|l|}
\hline Karakteristik & $\begin{array}{l}\text { Karakteristik } \\
\text { Dominan }\end{array}$ & $\begin{array}{l}\text { Jumlah } \\
\text { (Orang) }\end{array}$ & $\begin{array}{l}\text { Persentase } \\
(\%)\end{array}$ \\
\hline $\begin{array}{l}\text { Jenis } \\
\text { Kelamin }\end{array}$ & Laki - laki & 68 & 56,198 \\
\hline Usia & $18-28$ Tahun & 49 & 40,495 \\
\hline $\begin{array}{l}\text { Tingkat } \\
\text { Pendidikan } \\
\text { Terakhir }\end{array}$ & S1 & 55 & 45,454 \\
\hline $\begin{array}{l}\text { Pekerjaan } \\
\text { Pendapatan }\end{array}$ & $\begin{array}{l}\text { Pegawai } \\
\text { Swasta }\end{array}$ & 40 & 33,057 \\
\hline $\begin{array}{l}\text { Asal Tujuan } \\
\text { Tujuan } \\
\text { Penerbangan }\end{array}$ & Lainnya & 56 & 46,280 \\
\hline $\begin{array}{l}\text { Frekuensi } \\
\text { Penerbangan }\end{array}$ & $<2 x$ & 114 & 59,504 \\
\hline
\end{tabular}

Dari rekapitulasi data karakteristik yang terdapat pada Tabel 4 yang mendominasi adalah karakteristik berdasarkan: Jenis Kelamin didominasi oleh laki-laki berjumlah 68 orang dengan persentase $56.19 \%$. Usia didominasi tingkat usia 18-28 tahun sebanyak 49 orang dengan persentase $40.49 \%$. Tingkat Pendidikan Terakhir didominasi tingkat pendidikan S1 sebanyak 55 orang dengan persentase $45.45 \%$. Pekerjaan didominasi oleh Pegawai Swasta sebanyak 40 orang dengan persentase $33.05 \%$. Pendapatan didominasi dengan pendapatan perbulan Lainnya (selain $<$ Rp 2 Juta, Rp 2 Juta - Rp 4 Juta, Rp 4 Juta - Rp 5 Juta, dan > Rp 5 Juta) sebanyak 56 orang dengan persentase $46.28 \%$. Asal Tujuan didominasi dari Asal Tujuan Lainnya (selain Malang, Pasuruan, dan Surabaya/Sidoarjo) sebanyak 72 orang dengan persentase 59.50\%. Tujuan Penerbangan didominasi tujuan penerbangan Jakarta sebanyak 114 dengan persentase 94.21\%. Frekuensi Penerbangan didominasi dengan Frekuensi Penerbangan $<2 x$ sebanyak 80 orang dengan persentase $66.11 \%$.

\section{Analisis Data Menggunakan Rumus CSI}

Dari anlisis data diketahui nilai rata-rata pada kolom Kepentingan (I) didapatkan melalui penyebaran kuesioner kepentingan; sedangkan nilai rata-rata pada kolom Kepuasan (P) didapatkan melalui penyebaran kuesioner kepuasan. Setelah didapatkan total keseluruan Skor (S) dari hasil perkalian (I) dengan (P), kemudian dihitung menggunakan rumus CSI. Diketahui untuk $\mathrm{T}$ didapatkan dari total Skor (S) nilai 5 pada (5Y) adalah nilai maksimum yang digunakan pada skala pengukuran dikalikan total Kepentingan (I).

$$
\begin{aligned}
C S I & =T / 5 Y \times 100 \% \\
& =479.3 / 5 \times 123.8 \times 100 \% \\
& =77.43 \%
\end{aligned}
$$


Nilai tingkat kepuasan pelanggan sebesar $77,43 \%$. Hasil CSI dalam Tabel 2.2 Kriteria Tingkat Kepuasan Pelanggan berada pada kategori Puas.

\section{Analisis Data Ketidakpuasan Penumpang} adalah:

Penilaian Ketidakpuasan Penumpang paling dominan

- Presepsi responden mengenai atribut ke 12 Kehandalan peralatan dan fasilitas seperti, ac, televisi, dan lainnya diketahui 49 orang menyatakan Kurang Puas sampai dengan sangat tidak puas.

- Presepsi responden mengenai atribut ke 13 Kemudahan mendapatkan inter moda seperti, taxi, bus, dan lainnya diketahui 51 orang menyatakan Kurang Puas sampai dengan Sangat Tidak Puas.

- $\quad$ Presepsi responden mengenai atribut ke 14 Acara khusus yang diadakan pihak bandara seperti, promo tiket di waktu tertentu diketahui 56 orang menyatakan Kurang Puas sampai dengan Sangat Tidak Puas.

\section{KESIMPULAN}

Berdasarkan data hasil analisis terkait dengan penelitian ini, maka dapat ditarik beberapa kesimpalan sebagai berikut :

1. Berdasarkan data karakteristik responden berdasarkan jenis kelamin didapatkan Laki - laki berjumlah 68 orang dengan persentase $56.19 \%$, dan Perempuan berjumlah 53 orang dengan persentase $43.80 \%$. Data karakteristik responden berdasarkan usia didapatkan usia $<17$ Tahun sebanyak 5 orang dengan persentase $4.13 \%$, usia 18-28 Tahun sebanyak 49 orang dengan persentase $40.49 \%$, usia 29-39 Tahun sebanyak 22 orang dengan persentase $18.18 \%$, usia $40-49$ Tahun sebanyak 24 orang dengan persentase $19.83 \%$, dan usia $>50$ Tahun sebanyak 21 orang dengan persentase $17.35 \%$. Data karakteristik responden berdasarkan tingkat pendidikan terakhir didapatkan SMU/sederajat sebanyak 24 orang dengan persentase $19.83 \%$, D3 sebanyak 8 orang dengan persentase $6.61 \%, \mathrm{~S} 1$ sebanyak 55 orang dengan persentase $45.45 \%$, S2 sebanyak 27 orang dengan persentase $22.31 \%$, S3 sebanyak 4 orang dengan persentase $3.30 \%$, dan tingkat pendidikan lainnya sebanyak 3 orang dengan persentase $2.47 \%$. Data karakteristik responden berdasarkan pekerjaan didapatkan Pelajar/Mahasiswa sebanyak 20 orang dengan persentase $16.52 \%$, PNS sebanyak 16 orang dengan persentase $13.22 \%$, Pegawai Swasta sebanyak 40 orang dengan persentase $33.05 \%$, Wiraswasta sebanyak 19 orang dengan persentase $15.70 \%$, dan pekerjaan lainnya sebanyak 26 orang dengan persentase $21.48 \%$. Data karakteristik responden berdasarkan pendapatan didapatkan gaji < Rp. 2.000.000 sebanyak 11 orang dengan persentase $9.09 \%$, gaji Rp. 2Jt - Rp. 4Jt sebanyak 26 orang dengan persentase $21.48 \%$, gaji Rp. 4Jt - Rp. 5Jt sebanyak 13 orang dengan persentase $10.74 \%$, gaji > Rp. 5.000.000 sebanyak 15 orang dengan persentase $12.39 \%$, dan gaji lainnya sebanyak 56 orang dengan persentase $46.28 \%$. Data karakteristik responden berdasarkan asal tujuan didapatkan asal tujuan Malang sebanyak 49 orang dengan persentase $40.49 \%$, asal tujuan Pasuruan sebanyak 0 orang dengan persentase $0 \%$, asal tujuan Surabaya/Sidoarjo sebanyak 0 orang dengan persentase $0 \%$, asal tujuan Lainnya sebanyak 72 orang dengan persentase $59.50 \%$. Dari data karakteristik responden berdasarkan tujuan penerbangan didapatkan tujuan Jakarta sebanyak 114 orang dengan persentase $94.21 \%$, tujuan Bandung sebanyak 0 orang dengan persentase $0 \%$, tujuan Surabaya sebanyak 0 orang dengan persentase $0 \%$, tujuan Denpasar sebanyak 1 orang dengan persentase $0.82 \%$, tujuan lainnya sebanyak 6 orang dengan persentase $4.95 \%$. Data karakteristik responden berdasarkan frekuensi penerbangan didapatkan $<2 \mathrm{x}$ berjumlah 80 orang dengan persentase 66.11 $\%, 2-4 \mathrm{x}$ berjumlah 28 orang dengan persentase $23.14 \%$, dan $>4 \mathrm{x}$ berjumlah 13 orang dengan persentase $10.74 \%$.

2. Berdasarkan hasil dan analisis data, dapat disimpulkan bahwa: 1. Karakteristik penumpang paling dominan di Bandar Udara Abdulrachman Saleh Malang adalah responden yang berjenis kelamin laki-laki, berusia 18-28 tahun, berpendidikan S1, bekerja sebagai pegawai swasta, dengan pendapatan bisa kurang dari Rp. 2000.000,- atau lebih dari Rp. 5000.000,- berasal dari luar kota Malang, Pasuruan, Surabaya dan Sidoarjo, yang akan melakukan tujuan penerbangan ke Jakarta dengan frekuensi penerbangan $<2 \mathrm{x}$ dalam satu bulan.

3. Hasil analisis tingkat kepuasan pengunjung terhadap fasilitas umum di Bandar Udara Abdulrachman Saleh Malang dengan menggunakan metode Customer Satisfaction Index (CSI) adalah 77,43 \% dan masuk dalam kategori Puas. Ketidakpuasan pelanggan untuk kinerja pelayanan

\section{DAFTAR PUSTAKA}

Darus, M. D., \& Mahalli, K. (2015). Analisis Tingkat Kepuasan Penumpang Terhadap Kualitas Pelayanan Di Bandar Udara Internasional Kualanamu. Ekonomi dan Keuangan, 3(6).

Irawati, R., Wirangga, A., \& Hati, S. W. (2012). Analisa Kepuasan Pelanggan Bandar Udara Hang Nadim Batam. Jurnal Integrasi, 4(2), 159-167.

Mardoko, A. (2015). Tingkat Kepuasan Penumpang Terhadap Layanan Maskapai Penerbangan PT. Lion Air Route Mamuju-Jakarta. WARTA ARDHIA, 41(1), 19-28. 
Mariana, I. K., Sulistio, H., \& Arifin, M. Z. (2015). Kajian Tingkat Kepuasan Penumpang dan Kinerja Pelayanan Terminal Penumpang Domestik (T2) di Bandar Udara Internasional Juanda Surabaya. Rekayasa Sipil 9.3, 168-178.

Normasari, S. (2013). Pengaruh Kualitas Pelayanan Terhadap Kepuasan Pelanggan, Citra Perusahaan Dan Loyalitas Pelanggan Survei Padatamu Pelanggan Yang Menginap Di Hotel Pelangi Malang. Jurnal Administrasi Bisnis 6(2).

Pohandry, A., Sidarto, S., \& Winami, W. (2013). Analisis Tingkat Kepuasan Pelanggan Dengan Menggunakan Metode Customer Satisfaction Index Dan Importance Performance Analysis Serta Service Quality. Jurnal Rekavasi 1 no. 1.

Sugiyono, P. D. (2006). Metode Penelitian Bisnis. Bandung: Alfabeta.

Sugiyono, P. D. (2010). Metode Penelitian Pendidikan. Pendekatan Kuantitatif.

Wibowo, W., \& Iwan Rudianto. (2017). Pengaruh Karakteristik Penumpang Pesawat Terhadap Peluang Pemilihan Moda Menuju Bandara Baru Kulonprogo. JURNAL PEMBANGUNAN WILAYAH \& KOTA 13.4, 519-530.

Zulaichah, \& Nahar, F. (2013). Sistem Pengelolaan Keamanan Penerbangan Untuk Mendukung Rencana Peningkatan Status Bandar Udara Menjadi Bandar Udara Internasional (Studi Kasus

di Bandar Udara Abdulrachman Saleh - Malang). WARTA ARDHIA 39, no. 3, 192-206. 
Jurnal Rekayasa Tenik Sipil Universitas Madura Vol. 2 No.1 Juni 2019 ISSN 2527-5542

\section{Halaman Ini Sengaja Dikosongkan}

